\title{
Wishful thinking and the abandonment of moving desires over the life course
}

\begin{abstract}
Many longitudinal analyses of residential mobility decision-making use two or three waves of panel survey data to investigate who fulfils their moving desires. Few studies have, however, focused upon individuals who desire to move but who remain residentially immobile, either because it takes them a long time to relocate or because they abandon their moving desire. This is problematic, as undesired residential immobility could have negative consequences for individual well-being and prosperity. To address this research gap, this study uses 1991-2008 British Household Panel Survey data to analyse the duration and abandonment of moving desires. Importantly, the results show that the risk of abandoning a desire to move rises dramatically with age, suggesting that the well-documented residential rootedness of older people is not solely volitional. Event history analysis shows that these patterns are partly due to changing levels of ties and commitments over the life course. By demonstrating that ethnicity and income are also linked to the fulfilment of moving desires, the findings contribute to our understanding of the processes producing both social inequality and neighbourhood stratification.
\end{abstract}

Key words: Residential mobility; moving desires; longitudinal analysis 


\section{Introduction}

In response to Sheller and Urry's (2006) call for a new mobilities paradigm in social science, researchers are becoming increasingly interested in identifying, conceptualising and analysing a huge variety of practices and experiences of mobility. Perhaps unsurprisingly, this 'mobilities turn' has been enthusiastically embraced by many scholars interested in migration and residential mobility behaviour (King, 2012). As a result of this growing interest in movements and mobilities, comparatively few attempts have been made to better understand the considerable periods of time many people spend living in the same dwelling and neighbourhood (Cooke, 2011; King, 2012). This is somewhat surprising, given that most people relocate relatively infrequently and as spatial moorings remain important for migrants (King, 2012).

While many studies treat residential immobility as a homogenous process defined by an absence of moves (Hanson, 2005), not moving can be either a choice or the outcome of a lack of choice. Making this distinction requires separating 'rooted' nonmovers who do not desire to move from those 'wishful thinkers' who harbour a desire to relocate (Sell and De Jong, 1983). Given the costs and disruption induced by residential moves, as well as the increasing ease of using long commutes or teleworking as a substitute for migration, it is unsurprising that many people choose to relocate relatively infrequently (Fischer, 2002). However, it also seems likely that many immobile people desire to move but are unable to do so. Life course theory suggests that this may be because household scale restrictions, such as low levels of income or the needs of dependent children, constrain people's freedom to relocate (Mulder and Hooimeijer, 
1999). In addition, the macro context may inhibit desired residential moves. This is likely be particularly relevant in the current economic context, as research shows that many households find moving to be increasingly difficult during housing busts and periods of high unemployment (Ferreira et al, 2010; Hacker, 2000).

Residential immobility is likely to be a much less positive experience for wishful thinkers than for rooted individuals who have chosen not to move. As people seek to move to adjust their housing consumption to satisfy their changing needs over the life course (Clark and Huang, 2004), a persistent inability to satisfy these needs through relocation may have negative effects on individual well-being and prosperity (Ferreira and Taylor, 2009). This may pose a particular problem for the social justice agenda, if individuals who live in the least desirable places are those who also lack the resources to fulfil their moving desires. At the macro scale, the operation of housing and labour markets may be hindered if people cannot realise their moving desires by 'matching' themselves to appropriate job and dwelling vacancies (Wheaton, 1990).

Most previous analyses of moving desires have explored which individuals who wish to move at year $t$ have actually moved by year $t+x$ (Coulter et al, 2011; Landale and Guest, 1985; Speare et al, 1975). As a result, little is known about the length of time it takes individuals to fulfil their moving desires through relocation. This is problematic, as spending long periods of time desiring to move is likely to have greater negative consequences than being immediately able to fulfil a moving desire. In addition, research has neglected that wishful thinkers can also exercise their agency while not moving. Conceptually, this can occur through the abandonment of moving desires, either in response to unexpected life events (De Groot et al, 2011) or because the 
person perceives actually moving to be impossible. Desire abandonment could therefore be seen to be an important strategy for the reduction of cognitive dissonance, which Festinger et al (1956) argued occurs when people harbour two conflicting cognitions (in this case that moving is desirable but also impossible). As most studies focus only on who acts upon their moving desires, little is known about whether individuals abandon their moving desires when actually moving is not feasible.

To investigate these issues, this study uses data from the British Household Panel Survey (BHPS) to address two interlinked objectives. Firstly, the study aims to enhance our understanding of the emergence and duration of wishful spells. Secondly, the paper seeks to gain insight into why people abandon their moving desires. By focusing upon the duration of wishful spells and the abandonment of moving desires, the study contributes to our understanding of how moving desires relate to actual (im)mobility behaviour over individual life course biographies.

\section{Conceptual framework}

A long tradition of behavioural research has sought to understand how individuals make moving decisions (Halfacree and Boyle, 1993). Within this literature, relocation decisions are typically conceptualised as passing through a series of decision-making phases (Kley, 2011). While many studies recognise that this decision-making process often takes a long time and may not result in an actual move (Brown and Moore, 1970; De Jong and Fawcett, 1981), few have explicitly theorised or analysed these aspects of 
mobility decisions. This results in a somewhat partial conceptualisation of individual agency (Halfacree and Boyle, 1993), hindering our understanding of how people make decisions to live in different places.

To address this research gap, Figure 1 presents a conceptual schema of the mobility decision-making process. The model focuses on volitional moves which are not directly triggered by life events, as 'forced' moves (for instance due to eviction or following union dissolution) may not be anticipated or desired and hence may follow a radically different decision-making pathway (Coulter et al, 2011). Step 1 of Figure 1 shows that the first stage of the decision-making process is often the emergence of a desire to move (Rossi, 1955). Whether or not a desire to move is expressed at a given moment therefore distinguishes rooted individuals who are immobile through choice from those wishful thinkers who would prefer to live elsewhere. The emergence of a moving desire occurs in response to the disequilibrium generated when the needs, preferences and aspirations of household members are not being fulfilled in their current dwelling and neighbourhood (Rossi, 1955). Conceptually, life course theory indicates that rising disequilibrium can be driven by gradual changes in the life careers of household members (such as the gradual perception of a lack of space in the dwelling), as well as more sudden life events such as childbirth, completing school or changing jobs (Mulder and Hooimeijer, 1999; Rabe and Taylor, 2010).

\footnotetext{
${ }^{* * *}$ Figure 1 about here ${ }^{\star * *}$
} 
In the classic view, perceiving disequilibrium generates 'housing stress', which is often articulated as dissatisfaction with dwelling and neighbourhood conditions (Brown and Moore, 1970; Speare et al, 1975). Given the considerable cognitive demands of moving decisions as well as the costs and disruption induced by relocating, Mulder (1996) argues that people do not continuously consider moving in response to dissatisfaction. Instead and as Figure 1 demonstrates, individuals exercise bounded rationality, only expressing a desire to move once housing stress and dissatisfaction have exceeded a person-specific threshold of tolerance (Lu, 1998; Mulder, 1996; Speare et al, 1975). Psychological theories term this transition from rooted to becoming a wishful thinker to be the predecisional phase of mobility decision-making (Kley, 2011). In this phase, the person is considering relocation but has not yet committed themselves to moving.

According to Kley (2011), expressing a moving desire indicates that an individual judges that they could be more satisfied in an alternative location. This fits well with the value-expectancy model of mobility decision-making (De Jong and Fawcett, 1981), which posits that people relocate as they expect moving to enable them to fulfil their life goals. Different types of goals are often considered to motivate different types of moves. In this framework, long distance moves are thought to be mainly driven by economic factors, while people typically move shorter distances for non-economic reasons (Niedomysl, 2010). As both types of moves are undertaken in response to disequilibrium, long and short distance moving decisions may however follow a similar process of deliberation. 
Step 2 of Figure 1 shows that the duration and outcome of a wishful spell is then influenced by how feasible and urgent the individual perceives actually moving to be. In this framework, the urgency of moving refers to the strength of the moving desire, as well as the immediacy with which moving is required. Figure 1 proposes that wishful individuals who perceive moving to be more urgent and more feasible are more likely to quickly fulfil their moving desires through residential mobility. Psychological theories indicate that this is because these individuals are more likely to perceive that they possess the necessary behavioural control to attain their more highly valued goals (Kley, 2011; Lu, 1999; Lu, 1998). Wishful thinkers who perceive moving to be urgent and feasible are therefore likely to rapidly commit themselves more fully to moving by expressing firm intentions, plans or expectations of relocating (De Groot et al, 2011). Expressing a moving intention, plan or expectation indicates that an individual has entered the preactional phase of mobility decision-making, as they are actively striving to relocate (Kley, 2011). In Figure 1, this transition from the predecisional to preactional phase of decision-making occurs while evaluating the feasibility and urgency of moving.

As the feasibility and urgency of moving drops, the duration until fulfilment increases. This occurs because the individual has either less motivation to move or less control over their moving behaviour, increasing the length of the decision-making process. As the duration until fulfilment increases with decreasing feasibility and urgency, it also becomes more likely that a wishful spell will end in the abandonment of the moving desire. While the abandonment of desires is likely to take a considerable period of time if the individual perceives moving to be quite urgent and feasible, people are likely to more quickly abandon highly infeasible or non-urgent desires. 
Abandonment is likely to occur because individuals seek to avoid the uncomfortable cognitive dissonance generated by desiring to move while also perceiving that moving is impossible (Festinger et al, 1956). The abandonment of moving desires is likely to take place before wishful individuals enter the preactional phase of decision-making by expressing moving intentions or expectations, as abandoning these thoughts is often damaging for psychological well-being (Kley, 2011).

Figure 1 indicates that the feasibility and urgency of moving are influenced by a number of factors. Although these factors have well-documented effects on actual moving behaviour (Clark and Dieleman, 1996; Rabe and Taylor, 2010), little is known about how they influence the duration of wishful spells or the likelihood of desire abandonment. In addition to the constraints imposed by the labour and housing markets (Mulder and Hooimeijer, 1999), Figure 1 shows that life course ties are hypothesised to affect the duration and outcome of wishful spells. Possessing ties such as a partner or children of school-age increases the complexity of making an initial decision to move and then choosing a new dwelling (Seavers, 1999), thereby increasing the duration of decision-making and the risk of desire abandonment. Disagreements between partners over whether moving is desirable are likely to constitute a particularly strong life course tie (Coulter et al, 2012). It can therefore be hypothesised that:

1) Higher levels of life course ties are associated with taking longer to fulfil a moving desire and a greater risk of this desire being abandoned 
Secondly, the level of commitments a person possesses is likely to alter the feasibility of moving and hence their ability to quickly fulfil a moving desire. According to Feijten (2005), life course commitments can be thought of as states in the life careers of individuals from which it is difficult and costly to exit. Entering into committed states, such as getting married or buying a house, therefore restricts the future options of those entering into the commitment. Hence, desiring to move while possessing commitments is likely to be associated with a lengthier decision-making process and a greater risk of desire abandonment, as the decision to move and the choice of a new dwelling will be more complex and costly. This leads to the second hypothesis:

2) Higher levels of life course commitments are associated with taking longer to fulfil a moving desire and a greater risk of this desire being abandoned

An individual's access to resources is likely to configure both the feasibility and urgency of moving. On the one hand, higher levels of resources gained through employment and income should increase the geographical and tenure options available to households (Clark and Dieleman, 1996). However, the urgency of moving may be reduced for individuals with greater access to resources, as higher earners are likely to already live in more desirable places. In addition, access to resources is likely to increase the ability of individuals to adjust their dwelling in situ without the need for a costly and disruptive move (Littlewood and Munro, 1997). Nevertheless, after controlling for indicators of housing and neighbourhood quality, it can be hypothesised that: 
3) Greater access to socio-economic resources is associated with being able to more quickly fulfil a moving desire and a lower risk of this desire being abandoned

Finally, life events such as household changes or unemployment are known to affect the trajectory of moving decisions (De Groot et al, 2011). Such events could make moving more urgent, for instance following the birth of a child. However, life events could also reduce the urgency or feasibility of moving and trigger the abandonment of a moving desire. As a result, it is hard to formulate a specific hypothesis regarding the influence of life events on the duration and outcome of wishful spells.

By testing the three hypotheses and investigating how life events affect the duration and outcome of wishful spells, this paper enhances our understanding of how restrictions and constraints can impede people from realising their housing preferences. Over time, remaining a wishful thinker or abandoning a moving desire could have negative effects on individuals' well-being and prosperity. Identifying who is unable to act upon their residential preferences is also important for our understanding of the social dynamics of neighbourhoods. This is because individuals who spend long periods of time desiring to leave particular neighbourhoods may retreat from investing or participating in their local area, potentially contributing to neighbourhood decline (van der Land and Doff, 2010). 


\section{Data and Methods}

This study draws upon eighteen waves of BHPS data covering the years 1991-2008. During the first sweep of the BHPS in 1991, approximately 10,300 individuals in 5,500 households completed detailed interviews (Taylor et al, 2010). These individuals have since been tracked and re-interviewed each subsequent year. Extra households from Wales, Scotland and Northern Ireland were later added to the panel and have been tracked since 1999 (Wales and Scotland) and 2001 (Northern Ireland) (Taylor et al, 2010).

The BHPS is an ideal resource for this study, as information about each respondent's moving desires and actual moving behaviour is gathered at each interview. Whether or not an individual desired to move at each wave was identified from the answer given to the question 'If you could choose, would you stay here in your present home or would you prefer to move somewhere else?' By guiding respondents to report their relocation preferences regardless of whether or not they feel able to actually relocate, this question gathers information on moving desires rather than more firm moving intentions, plans or expectations. Thus, this question enables us to identify people who want to move but who feel too constrained to intend or expect to do so. Although this is a valuable feature of the survey question, the lack of detailed information on the strength of moving desires does mean that there is likely to be considerable heterogeneity amongst wishful thinkers, who may have diverse reasons for desiring to move. 
It was then necessary to identify spells where the person was a wishful thinker. Wishful spells could begin in one of two ways. Firstly, wishful spells could commence when a non-moving individual first expressed a desire to move after reporting no desire at the last wave. Secondly, wishful spells could begin when a person made a residential move and immediately desired to relocate again. In essence, becoming a wishful thinker required individuals to experience some kind of transition event. Once an individual became a wishful thinker, they were considered to be 'at risk' of their wishful spell terminating in one of two ways. Wishful spells could be terminated through a residential move (desire fulfilment), or through the abandonment of the moving desire. As wishful thinkers can be thought to be continuously at risk of experiencing either of these events, desire fulfilment and abandonment can be understood as 'competing risks' (Singer and Willett, 2003). Spells could also be terminated by either attrition or non-response if an individual's moving desires or their subsequent moving behaviour were unknown at a given year. These spells were retained but treated as censored.

A particular advantage of the BHPS is its favourable rates of participant attrition (see Taylor et al, 2010), although Buck (2000) notes that attrition correlates with mobility. Nevertheless, Rabe and Taylor (2010: 538) argue that there is little evidence for this attrition inducing selection biases in year-to-year analyses of moving behaviour. Although the focus on duration makes this study more vulnerable to selective attrition, the bias this could induce is dampened by including incomers to the BHPS after 1991 in the sample. In addition, informative censoring is partially controlled by including lagged predictors of attrition in the event history models. While attrition bedevils all panel surveys, prospective panel data gathered over a long time period are the only suitable 
source of data for this project. While retrospective surveys and population registers can provide longitudinal data with limited attrition, they cannot gather the requisite subjective data from individuals as they move through time.

By constructing variables counting the length of each spell for each person-year, it was possible to also analyse the duration of wishful spells. As information on moving desires was only gathered at each annual interview, all analyses were conducted within a discrete-time framework (see Singer and Willett, 2003). Continuous-time analysis would be rendered problematic by the large number of spells with a tied duration present in the sample (Singer and Willett, 2003). It is important to recognise that more than one spell per individual can be included in the analyses. This is because focusing on only one spell per individual is neither efficient nor consistent with the biographical approach advocated by life course theory.

\section{Analysis}

\section{Desire emergence}

Figure 1 indicates that the emergence of moving desires comprises the initial phase of mobility decision-making. To explore the factors associated with making this transition, it was necessary to focus on variations over time in whether individuals desired to move. This was achieved using a fixed effects logistic regression model with the expression of moving desires as the dependent variable ( $0=$ rooted, $1=$ wishful). Fixed effects models 
use only within-person variation on the dependent and independent variables, discarding all between-person variation using conditional maximum likelihood methods (Allison, 2009). This approach means that parameter estimates on the covariates can be interpreted as the effects of within-person changes in attributes on the likelihood of expressing moving desires (Allison, 2009: 33).

Unfortunately, adopting a fixed effects approach means that the effects of timeconstant variables cannot be estimated, although they are implicitly controlled (Allison, 2009). This restriction may be advantageous for the analysis of mobility decisionmaking, as using each individual as their own control takes into account that timeconstant unobservable factors (such as psychological characteristics) may affect relocation decisions. Given that the fixed effects model requires within-person variation on the dependent variable, all individuals who never changed from rooted to wishful were discarded. This left 135,116 person-years provided by 13,341 individuals (an average of 10.1 observations per person). Summary statistics for all variables included in the fixed effects model are presented in Table 1.

\section{${ }^{\star * *}$ Table 1 about here ${ }^{\star \star *}$}

Table 2 contains the results of a fixed effects logistic regression model analysing the expression of moving desires (reference rooted). Unsurprisingly, the results show that increases in age are associated with a reduced likelihood of desiring to move. Interestingly, partnership effects are stratified by whether the respondent's partner desires to move. A desire to move is much more likely to be expressed when an 
individual's partner also expresses a desire to move. This emphasises the importance of considering the agency of other 'linked' individuals in a person's household when analysing mobility decision-making and behaviour (Coulter et al, 2012).

${ }^{* * *}$ Table 2 about here ${ }^{* * *}$

Somewhat surprisingly, increasing numbers of children has a negative link to wishful thinking. This may be because roomstress is controlled and has a strong positive link to moving desires. Exiting the labour force is linked to a reduced likelihood of wishful thinking, while increasing income has the opposite effect (although this result is on the margins of statistical significance). This latter finding may indicate that people's housing and locational aspirations change with their socio-economic position, altering how they perceive and evaluate their current residential circumstances.

Housing tenure and recent residential mobility have strong links to the expression of moving desires. Individuals are more likely to express moving desires when living in social or particularly private rental housing when compared to periods spent in homeownership. As expected, residential mobility decreases the propensity for individuals to report desiring to move, although this effect is dampened by moving into rental housing. These results suggest that moving desires are stimulated by living in rented accommodation, perhaps due to the strong norms of homeownership present in British society. The importance of perceived dissatisfaction for the expression of moving desires is confirmed by the strong positive coefficient on the 'dislikes neighbourhood' dummy. Overall and in keeping with classic behavioural models of mobility decision- 
making (Rossi, 1955; Speare et al, 1975), these results suggest that moving desires typically emerge in response to the housing disequilibrium generated by residential dissatisfaction, unmet space needs and changes in the life course careers of household members.

\section{The duration and outcome of wishful spells}

Previous research has shown that the percentage of people expressing a moving desire is substantially higher than the percentage of people who actually move in a given year (Buck, 2000; Coulter et al, 2011). This suggests that either many people abandon their moving desires, or that it takes some people a considerable length of time to fulfil a desire to relocate. As a result, a key objective of this paper is to develop our understanding of the duration and outcome of wishful spells. This involves an analysis of step 2 of the mobility decision-making process outlined in Figure 1. As analysing the duration of wishful spells requires the spell to have an identifiable starting date, leftcensored observations where this could not be ascertained were discarded. In practice, this necessitated the removal of all person-years where the individual had not changed state since their first interview. Person-years where the individual was not a wishful thinker were also removed.

${ }^{* \star *}$ Figure 2 about here ${ }^{* \star *}$ 
To investigate the extent to which individuals abandon their moving desires over the life course, Figure 2 plots the percentage of wishful spells initiated at different ages against the eventual outcome of the spell. Spells ending in censorship (c.20-30\% in each age bracket) are omitted. The figure clearly shows that the probability of a wishful spell ending with either of the competing events changes dramatically over the life course. The percentage of spells ending in fulfilment peaks early in the life course, before dropping steadily with age. In contrast, the percentage of wishful spells ending in desire abandonment rises from a low of $21.9 \%$ of spells initiated in the early twenties to a high of over $65 \%$ in the late sixties and seventies. This pattern may indicate that the feasibility of moving varies systematically over the life course. For instance, it may be that the accumulation of ties and commitments with age constrains the feasibility of realising a moving desire to a greater extent than rising access to resources facilitates fulfilment.

Alternatively, it is also possible that the pattern visible in Figure 2 occurs because the urgency and motivations for desired moves change over the life course. While young people frequently make urgent moves to make significant changes in their household, education or labour force careers, older individuals may be more likely to desire to move for more discretionary reasons related to housing or neighbourhood dissatisfaction (Niedomysl, 2010). As the concept of housing careers suggests that many people accumulate wealth and select into more desirable dwellings and locations as they grow older, it seems possible that abandoning a moving desire also becomes less costly with age. Finally, older people may also be less reluctant to jettison a moving desire, as they have less time to recoup the benefits of relocation. 
In order to link this analysis to an investigation of spell duration, Table 3 presents a life table of all 23,297 wishful spells initiated by BHPS respondents. The left hand column indicates the current length of each spell, while the second column documents how many spells reach this duration (Singer and Willett, 2003). The fulfilment, abandonment and censorship count columns indicate how many spells are terminated over the next year by each of the competing events. The event-specific hazard functions are derived by dividing the risk set (column 2) by the counts (columns 4 or 6 ) for each duration and event type. This assumes that censoring is non-informative, with censored cases not differing significantly from those experiencing the competing events. This could be problematic if those people who are least likely to fulfil their moving desires quickly abandon them (and vice versa), an issue which will subsequently be addressed using event history models.

\section{${ }^{* * *}$ Table 3 about here ${ }^{\star * *}$}

As duration rises, the risk of a spell ending through either fulfilment or abandonment drops rapidly. Although most spells are comparatively short, it is interesting to note that a sizeable minority of spells last longer than five years. This suggests that year-to-year longitudinal analyses may miss considerable heterogeneity within the pool of wishful thinkers, as some will have been desiring to move for much longer than others. In the first year after becoming a wishful thinker, the hazard rate of abandoning this desire is greater than the likelihood of it being fulfilled. This pattern largely persists as spell duration rises. These declining hazard rates seem to suggest 
that people become less likely to fulfil or abandon their desires the longer their spell lasts. As noted by Singer and Willett (2003), this may be caused by the unobserved heterogeneity of wishful thinkers. If those judging moving to be very urgent and feasible move quickly, while those with the opposite view quickly abandon their desires, as duration rises the pool of wishful thinkers becomes increasingly comprised of those unwilling to abandon but unable to fulfil their moving desires. This is in itself interesting, suggesting that a sizeable group of individuals are reluctant to abandon infeasible moving desires.

To analyse how different factors affect the duration and termination of wishful spells and thus test the hypotheses, it is necessary to use event history models (Singer and Willett, 2003). The dependent variable is a three category nominal variable recording whether a wishful spell was ongoing, terminated by fulfilment, or terminated by abandonment at each person-year (the reference category is ongoing). This dependent variable measures whether the termination event occurred between waves $t$ and $t+1$, while the independent variables in the models contain wave $t$ lagged values (Table 4 for summary statistics). A series of spell duration dummies are included in the models to capture the baseline hazard function (Singer and Willett, 2003). As the dependent variable is nominal, a multinomial logistic regression model was used to estimate the likelihood of spells being terminated by fulfilment and abandonment (BoxSteffensmeier and Jones, 2004). This allows fulfilment and abandonment to be treated as risks which continuously 'compete' to terminate wishful spells. As individuals could be observed in multiple separate spells which cannot be assumed to be independent, 
standard errors have been corrected for the clustering of person-year observations within individuals.

\section{*** Table 4 about here ${ }^{\star \star *}$}

This modelling strategy requires a number of assumptions. Firstly, the use of the multinomial framework requires accepting the Independence of Irrelevant Alternatives assumption. This states that "conditional on the covariates, the ratio of the probabilities of any two alternatives is independent of each of the other alternatives" (BoxSteffensmeier and Jones, 2004: 178). This does not seem to be unrealistic for this analysis, as moving and abandoning are dissimilar alternatives which individuals can probably evaluate independently (Long and Freese, 2006: 243-244). A second, more general assumption of the modelling framework is that censoring is non-informative (Singer and Willett, 2003). This could be problematic if there is selective attrition from the BHPS sample. As this assumption is conditional on the covariates (Singer and Willett, 2003: 591), care was taken to ensure that lagged independent variables were included to control for most of the predictors of BHPS attrition and non-response identified by Uhrig (2008). This included variables for housing type and two interviewer reported measures of participant engagement (Table 4 for details).

Consistent with Table 3, Model 1 in Table 5 indicates that the baseline hazard functions of both desire fulfilment and abandonment decrease with spell duration. This decline persists even when independent variables are added in Model 2, although the shape of the hazard functions change somewhat. The baseline risk of fulfilment 
becomes more strongly negative with the inclusion of independent variables, while the risk of abandonment changes less dramatically. Overall, these strong and highly significant effects of duration are important and indicate that examining whether a moving desire expressed at point $t$ is realised by $t+1$ misses considerable heterogeneity amongst wishful thinkers.

**Table 5 about here ${ }^{* * *}$

As hypothesised, many of the independent variables have opposite effects on the risk of experiencing each of the competing events. As age rises, the risk of fulfilment drops while the risk of abandonment increases. As these effects remain significant after controlling for life course characteristics and access to resources, this result suggests that increasing age may reduce the urgency of moving. This could be because many older individuals have already selected themselves into more desirable dwellings and locations, reducing the perceived costs of desire abandonment. Consistent with prior research and the first hypothesis (Ferreira and Taylor, 2009), whether the respondent is partnered and the moving desires of any partner have a strong impact on the risks of fulfilment and abandonment. Compared with wishful singles, individuals with a partner who agrees that moving is desirable have a greater risk of fulfilment and a lower risk of abandonment. The opposite is true for individuals whose partner does not wish to move, probably because the feasibility of moving is reduced when partners disagree.

In support of hypothesis one, school-age children seem to constitute a life course tie which lowers the risk of fulfilment and increases the risk of abandonment. As 
education level rises, the risk of desire fulfilment rises and the risk of abandonment drops. This provides some support for hypothesis three, as higher levels of education are typically linked to greater access to socio-economic and cultural resources. Given that many students migrate to attend university in the UK, this finding may also indicate that prior experience of mobility increases the perceived feasibility of making subsequent moves.

Housing tenure has close links to the duration and outcome of wishful spells, with private renters far more likely to realise a desire to move than homeowners. This is probably a compositional and contextual effect, as mobile people select into private rental housing due to the ease of making future moves within this sector. As anticipated, disliking the neighbourhood increases the risk of desire fulfilment while greatly decreasing the risk of desire abandonment. This is probably because disliking the neighbourhood increases the urgency of relocating. People who dislike their neighbourhood are therefore not only more likely to desire to move (Table 2), they are also far more likely to subsequently act upon this desire (Table 5). This finding indicates that policies aiming to promote community stability need to focus upon investing in neighbourhoods.

Given that desire fulfilment and abandonment can be considered to be competing risks, those independent variables which do not have opposite effects on these events are of particular interest. Intriguingly, ethnic minorities have a lower risk of fulfilment than whites, but no significantly different risk of abandonment. While we must be cautious in interpreting this effect given the small sample size, this result may suggest that ethnic minorities face additional barriers to making desired moves above 
and beyond those imposed by socio-economic resources. Alternatively, it is possible that ethnic minorities may be more likely to express preferences for less feasible international moves, perhaps for family or cultural reasons. In contrast, partnership changes seem to increase the risk of both abandonment and particularly fulfilment. These findings indicate that partnership changes catalyse mobility decision-making, either by stimulating residential adjustments or by triggering desire abandonment.

Employment status has interesting links to the duration and outcome of wishful spells. While being out of the labour force is associated with a greater risk of fulfilment and abandonment than being employed, unemployment reduces the risk of abandonment but has no significant link to fulfilment. This implies that the unemployed are reluctant to jettison their moving desires, perhaps because they perceive moving to be more urgent than the employed. While increasing income stimulates the expression of moving desires (Table 2), high levels of income also facilitate fulfilment (Table 5). In contrast, there is no evidence that people with lower incomes are significantly more likely to abandon their moving desires. This provides only partial support for hypothesis three, indicating that socio-economic constraints on the feasibility of moving may be an important factor in the production of socio-economically stratified neighbourhoods.

Interestingly, high levels of roomstress promote fulfilment but have no significant links to the abandonment of moving desires. The regional variables indicate that people living in England outside of London and the South-East are most likely to fulfil their moving desires. Wishful thinkers in London and the South-East are less likely to fulfil and abandon their moving desires, highlighting the difficulties faced by people seeking to move within these historically tight housing markets. Overall, the results provide 
broad support for the first two hypotheses. The models indicate that high levels of life course ties and commitments increase the length of time until a moving desire is fulfilled, while simultaneously increasing the risk of desire abandonment. There is somewhat more mixed support for hypothesis three, as employment status and income have more complex associations with desire fulfilment and abandonment.

\section{Conclusions}

To better understand the importance of spatial mobility over the life course, it is necessary to also investigate why people do not relocate (Cooke, 2011; Hanson, 2005). Residential immobility is an important process for many individuals, as spells of residential rootedness carry considerable cultural and emotional meaning (Mason, 2004). As psychological theories of mobility decision-making suggest that people seek to live in places which satisfy their life goals (De Jong and Fawcett, 1981; Lu, 1998), it is valuable to analyse how moving desires relate to subsequent moving behaviour. Most existing research in this area has used short segments of longitudinal data to assess who quickly fulfils their moving desires (Coulter et al, 2011; Landale and Guest, 1985). These studies show that many people with a desire to move have not fulfilled this desire one or two years later. This weak relationship could exist because it takes people a long time to fulfil their moving desires, or because many people abandon their desires to prevent experiencing cognitive dissonance. 
Analysing the emergence, duration and abandonment of wishful spells extends our knowledge of the extent to which residential immobility can be a choice or the outcome of a lack of choice. It is important to identify those individuals who are unable to act upon their moving desires, as this could have negative consequences for their subjective well-being and prosperity (Ferreira and Taylor, 2009). The implications of frustrated moving desires may also be felt at a wider scale, as the labour and housing markets require people to be able to match themselves to appropriate employment and housing vacancies (Wheaton, 1990).

To extend our understanding of wishful thinking and the abandonment of moving desires, the analyses first investigated the emergence of moving desires. The results reinforce the view that people express moving desires when their current dwelling no longer meets their needs and preferences (Rossi, 1955), as moving desires emerge when people experience space pressure in their current dwelling, start to dislike their neighbourhood or when their partner desires to move. The analysis then focused on the duration and outcome of wishful spells. In keeping with the theoretical model outlined in Figure 1, the analyses indicated that the feasibility and urgency of moving conditions the trajectory of wishful spells. Importantly, Figure 2 shows that the propensity to fulfil moving desires drops sharply with age, while the likelihood of abandoning a moving desire rises. This suggests that the familiar pattern of declining mobility rates with age does not occur simply because older people are less likely to want to move, but also because their moving desires are less urgent and/or feasible and are hence less likely to be fulfilled. 
As Figure 1 demonstrates that changes in the feasibility and urgency of making a desired move could be driven by changing levels of ties, commitments and socioeconomic resources over the life course, event history models were used to analyse the duration and outcome of wishful spells. The results support the hypotheses that people with greater levels of life course ties and commitments have a lower risk of fulfilling their moving desires and a higher risk of rapidly abandoning them. Given the strong effects of the global financial crisis on the British housing market, the constraining effects of homeownership commitments are likely to have become more acute since the end of the study period. Indeed, Rabe (2012) has shown that since 2009, it has been difficult for homeowners to immediately act upon their moving desires. This could suggest that both desired and undesired stability within the homeownership sector may increase in the near future, as mobile younger households find it difficult to access homeownership while existing homeowners find it harder to realise their moving desires.

Ethnicity, socio-economic status and life events appear to have more equivocal links to the duration and outcomes of wishful spells. Ethnic minorities and those with lower incomes are less likely to fulfil their moving desires than whites and those with a higher income, while having no significantly different propensity to abandon their desires. This suggests that these groups have a tendency to be persistently disadvantaged long-term wishful thinkers. This could have negative effects on their wellbeing, as these groups are disproportionately likely to live in the most deprived areas where levels of neighbourhood satisfaction are often lower (Rabe and Taylor, 2010). This could in turn reduce social cohesion in these areas, as qualitative evidence suggests that wishing to leave a neighbourhood leads people to avoid participating or 
investing in their local area (Van der Land and Doff, 2010). These findings suggest that over time, undesired immobility may contribute significantly to the production of socioeconomically disadvantaged neighbourhoods. Overall, investigating why people do not move even though they may want to remains essential if we are to better understand the causes and consequences of residential (im)mobility over the life course. 


\section{References}

Allison P, 2009, Fixed Effects Regression Models (Sage, London).

Box-Steffensmeier J, Jones B, 2004, Event History Modelling: A Guide for Social Scientists (CUP, Cambridge).

Brown L A, Moore E G, 1970, "The intra-urban migration process: A perspective" Geografiska Annaler. Series B, Human Geography 52 1-13.

Buck N, 2000, "Using panel surveys to study migration and residential mobility", in Researching Social and Economic Change: The Uses of Household Panel Studies. Ed. D Rose (Routledge, London) pp 250-272.

Clark W A V, Huang Y, 2004, "Linking migration and mobility: Individual and contextual effects in housing markets in the UK" Regional Studies 38617 - 628.

Clark W A V, Dieleman F, 1996, Households and Housing: Choice and Outcomes in the Housing Market (Centre for Urban Policy Research, New Brunswick).

Cooke T, 2011, "It is not just the economy: Declining migration and the rise of secular rootedness" Population, Space and Place 17 193-203. 
Coulter R, van Ham M, Feijten P, 2012, "Partner (dis)agreement on moving desires and the subsequent moving behaviour of couples" Population, Space and Place 18 16-30.

Coulter R, van Ham M, Feijten P, 2011, "A longitudinal analysis of moving desires, expectations and actual moving behaviour" Environment and Planning A 43 2742-2760.

De Groot C, Mulder C, Das M, Manting D, 2011, "Life events and the gap between intention to move and actual mobility" Environment and Planning A 43 48-66.

De Jong G, Fawcett J, 1981, "Motivations for migration: An assessment and a valueexpectancy research model" in Migration decision making: Multidisciplinary approaches to microlevel studies in developed and developing countries Eds G De Jong, J Fawcett. (Pergamon, Oxford) pp 13-58.

Feijten P, 2005, Life Events and the Housing Career: A Retrospective Analysis of Timed Effects (Eburon, Delft).

Ferreira F, Gyourko J, Tracy J, 2010, "Housing busts and household mobility" Journal of Urban Economics 68 34-45.

Ferreira P, Taylor M, 2009, "Residential mobility, mobility preferences and psychological health", in Changing Relationships Eds M Brynin, J Ermisch (Routledge, Oxford) pp 161-179. 
Festinger L, Riecken H, Schachter S, 1956, When Prophecy Fails: A Social and Psychological Study of a Modern Group that Predicted the Destruction of the World (Harper \& Row, New York).

Fischer C S, 2002, "Ever-more rooted Americans" City \& Community 1 177-198.

Hacker R, 2000, "Mobility and regional economic downturns" Journal of Regional Science 40 45-65.

Halfacree K, Boyle P, 1993, "The challenges facing migration research: the case for a biographical approach" Progress in Human Geography 17 333-348.

Hanson S, 2005, "Perspectives on the geographic stability and mobility of people in cities" Proceedings of the National Academy of Sciences of the United States of America 102 15301-15306.

King R, 2012, "Geography and migration studies: Retrospect and prospect" Population, Space and Place 18 134-153.

Kley S, 2011, "Explaining the stages of migration within a life-course framework" European Sociological Review 27 469-486. 
Landale N S, Guest A M, 1985, "Constraints, satisfaction and residential mobility: Speare's model reconsidered" Demography 22 199-222.

Littlewood A, Munro M, 1997, "Moving and improving: Strategies for attaining housing equilibrium" Urban Studies 34 1771-1787.

Long J S, Freese J, 2006, Regression Models for Categorical Dependent Variables Using Stata, Second Edition (Stata Press, Texas).

Lu M, 1999, "Do people move when they say they will? Inconsistencies in individual migration behavior" Population \& Environment 20 467-488.

Lu M, 1998, "Analyzing migration decision making: Relationships between residential satisfaction, mobility intentions, and moving behavior" Environment and Planning A $\mathbf{3 0}$ 1473-1495.

Mason J, 2004, "Personal narratives, relational selves: Residential histories in the living and telling" The Sociological Review 52 162-179.

Mulder C, Hooimeijer P, 1999, "Residential relocations in the life course", in Population Issues: An Interdisciplinary Focus Eds L van Wissen, P Dykstra (Plenum Press, New York) pp 159-186. 
Mulder C, 1996, "Housing choice: Assumptions and approaches" Journal of Housing and the Built Environment $11209-232$.

Niedomysl T, 2010, "How migration motives change over migration distance: Evidence on variation across socio-economic and demographic groups" Regional Studies 45 843855.

Rabe B, 2012, "Moving home: Wishes, expectations and reasons", in Understanding Society: Findings 2012 Eds S McFall (University of Essex, Colchester).

Rabe B, Taylor M, 2010, "Residential mobility, quality of neighbourhood and life course events" Journal of the Royal Statistical Society: Series A 173 531-555.

Rossi P H, 1955, Why Families Move: A Study in the Social Psychology of Urban Residential Mobility (Free Press, Glencoe).

Seavers J, 1999, "Residential relocation of couples: The joint decision-making process considered" in Migration and Gender in the Developed World, Eds P Boyle, K Halfacree. (Routledge, London) pp 151-171.

Sell R, De Jong G, 1983, "Deciding whether to move: Mobility, wishful thinking and adjustment" Sociology \& Social Research 67 146-165. 
Sheller M, Urry J, 2006, "The new mobilities paradigm" Environment and Planning A 38 207-226.

Singer J D, Willett J B, 2003, Applied Longitudinal Data Analysis: Modelling Change and Event Occurrence (OUP, Oxford).

Speare A, Goldstein S, Frey W, 1975, Residential Mobility, Migration, and Metropolitan Change (Ballinger, Cambridge).

Taylor M F (Ed) with Brice J, Buck N, Prentice-Lane E, 2010 British Household Panel Survey User Manual Volume A: Introduction, Technical Report and Appendices (University of Essex, Colchester).

Uhrig S C N, 2008, "The nature and causes of attrition in the British Household Panel Survey" Institute for Social and Economic Research Working Paper 2008-05, ISER, University of Essex.

Van der Land M, Doff W, 2010, "Voice, exit and efficacy: Dealing with perceived neighbourhood decline without moving out" Journal of Housing and the Built Environment 25 429-445.

Wheaton W, 1990, "Vacancy, search, and prices in a housing market matching model" Journal of Political Economy 98 1270-1292. 


\section{Figures and tables}

Figure 1. A conceptual model of the emergence, duration and outcome of wishful spells

STEP 1: Desire emergence

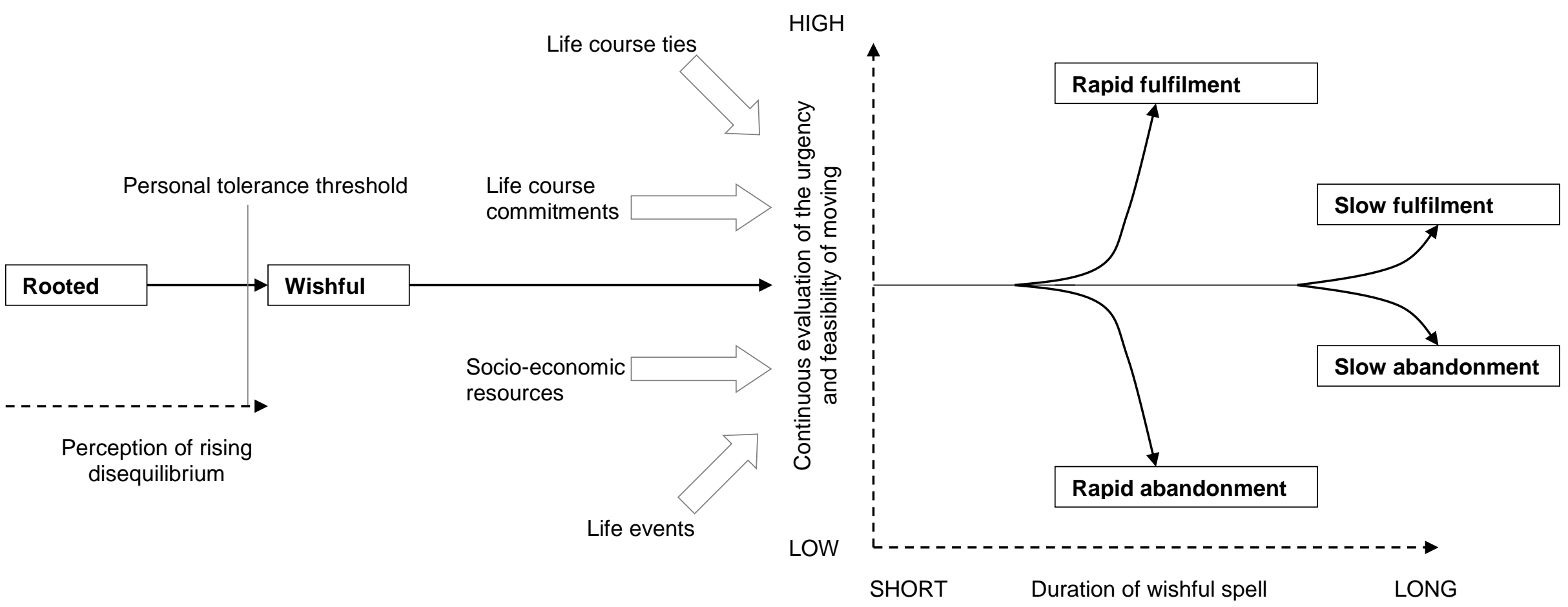


Figure 2. The outcomes of wishful spells by age at the start of the spell

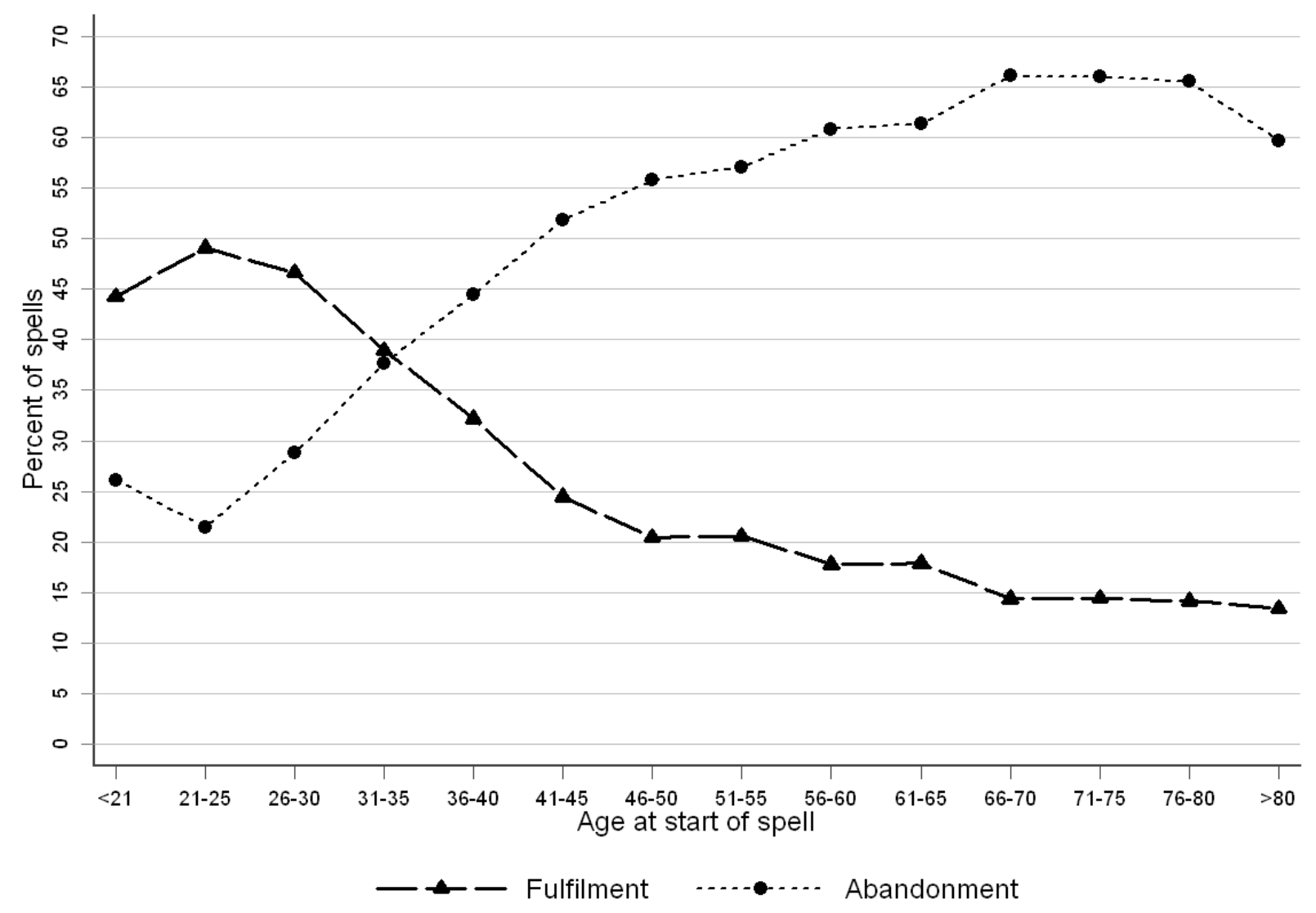




\section{Table 1. Summary statistics for variables included in the fixed effects model ( $n=135,116$ person-years)}

\begin{tabular}{|c|c|c|}
\hline Categorical variable & Frequency & $\%$ \\
\hline \multicolumn{3}{|l|}{ Expression of moving desires } \\
\hline no desire (rooted) (ref) & 81,043 & 59.98 \\
\hline desire (wishful thinker) & 54,073 & 40.02 \\
\hline \multicolumn{3}{|l|}{ Partnership and desire agreement } \\
\hline single (ref) & 45,603 & 33.75 \\
\hline couple, partner has no desire & 50,481 & 37.36 \\
\hline couple, partner desires & 31,166 & 23.07 \\
\hline couple, partner's desires missing & 7,866 & 5.82 \\
\hline \multicolumn{3}{|l|}{ Employment status } \\
\hline employed (ref) & 85,854 & 63.54 \\
\hline unemployed & 4,963 & 3.67 \\
\hline out of labour force & 44,299 & 32.79 \\
\hline \multicolumn{3}{|l|}{ Housing tenure } \\
\hline homeowner (ref) & 99,726 & 73.81 \\
\hline social renter & 22,913 & 16.96 \\
\hline private renter & 12,477 & 9.23 \\
\hline \multicolumn{3}{|l|}{ Mobility $t-1$ to $t$} \\
\hline no move (ref) & 117,902 & 87.26 \\
\hline move & 17,214 & 12.74 \\
\hline \multicolumn{3}{|l|}{ Liking the neighbourhood } \\
\hline likes (ref) & 123,651 & 91.51 \\
\hline dislikes & 11,465 & 8.49 \\
\hline Continuous variable & Mean & Std. dev. \\
\hline Age & 42.74 & 17.15 \\
\hline Number of dependent children & 0.73 & 1.04 \\
\hline Log of real household income ${ }^{1}$ & 9.95 & 0.69 \\
\hline Roomstress (n people/n rooms) ${ }^{2}$ & 0.67 & 0.31 \\
\hline
\end{tabular}


Table 2. Fixed effects logistic regression model of wishful thinking (ref rooted)

\begin{tabular}{|c|c|c|}
\hline Variable & Coefficient & Robust Std. Err. \\
\hline Age & $-0.085^{\star \star}$ & 0.027 \\
\hline Age squared & $-0.001^{* * *}$ & 0.000 \\
\hline \multicolumn{3}{|c|}{ Partnership and desire agreement (ref single) } \\
\hline couple, partner has no desire & $-1.110^{\star * \star}$ & 0.044 \\
\hline couple, partner desires & $1.314^{* * *}$ & 0.044 \\
\hline couple, partner desires missing & -0.038 & 0.058 \\
\hline Number of dependent children & $-0.207^{* \star *}$ & 0.018 \\
\hline \multicolumn{3}{|l|}{ Labour force participation (ref employed) } \\
\hline unemployed & -0.041 & 0.050 \\
\hline out of labour force & $-0.231^{* * *}$ & 0.032 \\
\hline Log household income & 0.033 & 0.017 \\
\hline \multicolumn{3}{|l|}{ Housing tenure (ref homeowner) } \\
\hline social rent & $0.287^{* * *}$ & 0.060 \\
\hline private rent & $0.386^{\star \star *}$ & 0.056 \\
\hline Moved since last wave (ref no move) & $-0.699 * * *$ & 0.033 \\
\hline social rent*move dummy & $0.147^{* *}$ & 0.067 \\
\hline private rent*move dummy & $0.210^{* * *}$ & 0.062 \\
\hline Roomstress & $0.711^{\star * *}$ & 0.051 \\
\hline Dislikes neighbourhood (ref likes) & $3.034^{\star * *}$ & 0.053 \\
\hline $\mathrm{N}$ (n groups) & $135116(13341)$ & \\
\hline Log-likelihood (improvement) & $-43464.2(12597.3)$ & \\
\hline Wald chi² (d.f.) & $11276(31)$ & \\
\hline AIC & 86990.3 & \\
\hline
\end{tabular}

Source: BHPS, author calculations

Note: Extra controls included for year of interview (not shown)

${ }^{* *} p<0.05{ }^{* * *} p<0.001$ 
Table 3. Life table describing the duration of wishful spells

\begin{tabular}{|c|c|c|c|c|c|c|c|}
\hline \multirow[t]{2}{*}{ Year of spell } & \multirow{2}{*}{$\begin{array}{l}n \text { wishful at } \\
\text { start of year }\end{array}$} & \multirow{2}{*}{$\begin{array}{c}\text { Time interval of event } \\
\text { occurrence }\end{array}$} & \multicolumn{2}{|c|}{ Fulfilment $t$ to $t+1$} & \multicolumn{2}{|c|}{ Abandonment $t$ to $t+1$} & \multirow[t]{2}{*}{ Censored $t$ to $t+1$} \\
\hline & & & Count & Hazard function & Count & Hazard function & \\
\hline 1 & 23,297 & {$[1,2)$} & 5,008 & 0.2150 & 6,367 & 0.2733 & 2,737 \\
\hline 2 & 9,185 & {$[2,3)$} & 1,553 & 0.1691 & 1,638 & 0.1783 & 1,328 \\
\hline 3 & 4,666 & {$[3,4)$} & 665 & 0.1425 & 685 & 0.1468 & 647 \\
\hline 4 & 2,669 & {$[4,5)$} & 338 & 0.1266 & 354 & 0.1326 & 371 \\
\hline 5 & 1,606 & {$[5,6)$} & 191 & 0.1189 & 168 & 0.1046 & 215 \\
\hline 6 & 1,032 & {$[6,7)$} & 113 & 0.1095 & 92 & 0.0891 & 115 \\
\hline 7 & 712 & {$[7,8)$} & 56 & 0.0787 & 62 & 0.0871 & 105 \\
\hline 8 & 489 & {$[8,9)$} & 32 & 0.0654 & 43 & 0.0879 & 73 \\
\hline 9 & 341 & {$[9,10)$} & 31 & 0.0909 & 26 & 0.0762 & 46 \\
\hline 10 & 238 & {$[10,11)$} & 13 & 0.0546 & 26 & 0.1092 & 30 \\
\hline 11 & 169 & {$[11,12)$} & 6 & 0.0355 & 11 & 0.0651 & 32 \\
\hline 12 & 120 & {$[12,13)$} & 4 & 0.0333 & 6 & 0.0500 & 19 \\
\hline 13 & 91 & {$[13,14)$} & 1 & 0.0110 & 9 & 0.0989 & 22 \\
\hline 14 & 59 & {$[14,15)$} & 4 & 0.0680 & 7 & 0.1186 & 13 \\
\hline 15 & 35 & {$[15,16)$} & 1 & 0.0286 & 2 & 0.0571 & 13 \\
\hline 16 & 19 & {$[16,17)$} & 0 & - & 1 & 0.0526 & 9 \\
\hline 17 & 9 & {$[17,18)$} & 0 & - & 0 & - & 9 \\
\hline
\end{tabular}


Table 4. Summary statistics for variables included in the multinomial model $(n=40,234)$

\begin{tabular}{|c|c|c|}
\hline Categorical variables & $\mathbf{N}$ & $\%$ \\
\hline Number of fulfilment events & 7,367 & 18.31 \\
\hline Number of abandonment events & 8,958 & 22.26 \\
\hline Female (ref male) & 21,316 & 52.98 \\
\hline Ethnic minority (ref white) & 1,374 & 3.42 \\
\hline \multicolumn{3}{|l|}{ Partnership status and moving desire agreement (ref single) } \\
\hline couple, partner disagrees & 7,932 & 19.71 \\
\hline couple, partner agrees & 16,232 & 40.34 \\
\hline couple, partner's desires are unknown & 2,253 & 5.60 \\
\hline \multicolumn{3}{|l|}{ Change in partnership status $t$ to $t+1$ (ref no change) } \\
\hline change & 2,120 & 5.27 \\
\hline unknown & 3,048 & 7.58 \\
\hline \multicolumn{3}{|l|}{ Presence and ages of dependent children (ref none) } \\
\hline all children $<5$ years old & 3,905 & 9.71 \\
\hline children aged 5 or over in household & 11,848 & 29.45 \\
\hline \multicolumn{3}{|l|}{ Child born to respondent $t$ to $t+1$ (ref no birth) } \\
\hline child birth & 1,584 & 3.94 \\
\hline unknown & 3,430 & 8.53 \\
\hline \multicolumn{3}{|l|}{ Education level (ref no qualifications) } \\
\hline low (basic secondary school qualifications-eg. GCSE) & 10,395 & 25.84 \\
\hline medium (advanced school/vocational qualifications-eg. A Level) & 16,491 & 40.99 \\
\hline high (university degree and above) & 5,914 & 14.70 \\
\hline other or unknown & 363 & 0.90 \\
\hline \multicolumn{3}{|l|}{ Employment status (ref employed) } \\
\hline unemployed & 1,882 & 4.68 \\
\hline out of the labour force & 11,350 & 28.21 \\
\hline \multicolumn{3}{|l|}{ Housing type (ref single family building) } \\
\hline flat & 7,062 & 17.55 \\
\hline other & 835 & 2.08 \\
\hline \multicolumn{3}{|l|}{ Housing tenure (ref homeowner) } \\
\hline social renter & 7,642 & 18.99 \\
\hline private renter & 5,585 & 13.88 \\
\hline Dislikes neighbourhood (ref likes) & 7,378 & 18.34 \\
\hline Uncooperative with interviewer (ref cooperative) & 655 & 1.63 \\
\hline Failed to provide complete tracking information (ref provided) & 868 & 2.16 \\
\hline \multicolumn{3}{|l|}{ Geographical region (ref rest of England) } \\
\hline London and SE England & 8,500 & 21.13 \\
\hline Wales & 4,612 & 11.46 \\
\hline Scotland & 5,529 & 13.74 \\
\hline N. Ireland & 1,923 & 4.78 \\
\hline Continuous variables & Mean & S.D. \\
\hline Age & 40.20 & 16.10 \\
\hline Log of real household income ${ }^{1}$ & 9.95 & 0.70 \\
\hline Roomstress (n people/n rooms) ${ }^{2}$ & 0.70 & 0.33 \\
\hline
\end{tabular}

Source: BHPS, author calculations

${ }^{1}$ Household incomes have been deflated to 2005 prices and adjusted using the McClement's Before Housing Costs scale, to take into account the effects of household size and structure on income needs.

${ }^{2}$ Number of rooms excludes bathrooms, kitchens and sublet rooms. 
Table 5. Multinomial logistic discrete-time event history model of desire fulfilment and abandonment (ref ongoing)

\begin{tabular}{|c|c|c|c|c|c|c|c|c|}
\hline \multirow[t]{3}{*}{ Variables $^{1}$} & \multicolumn{4}{|c|}{ Model 1} & \multicolumn{4}{|c|}{ Model 2} \\
\hline & \multicolumn{2}{|c|}{ Fulfilment } & \multicolumn{2}{|c|}{ Abandonment } & \multicolumn{2}{|c|}{ Fulfilment } & \multicolumn{2}{|c|}{ Abandonment } \\
\hline & Coeff. & Robust S.E. & Coeff. & Robust S.E. & Coeff. & Robust S.E. & Coeff. & Robust S.E. \\
\hline \multicolumn{9}{|l|}{ Duration of wishful spell (years) } \\
\hline 1 & $-0.886^{\star \star *}$ & 0.020 & $-0.611^{\star * *}$ & 0.017 & $-2.099^{* * *}$ & 0.309 & $-0.915^{\star \star *}$ & 0.258 \\
\hline 2 & $-1.247^{\star \star *}$ & 0.031 & $-1.180^{* * *}$ & 0.030 & $-2.461^{* * *}$ & 0.310 & $-1.548^{\star * *}$ & 0.260 \\
\hline 3 & $-1.505^{\star * *}$ & 0.045 & $-1.462^{\star * *}$ & 0.044 & $-2.715^{\star * *}$ & 0.313 & $-1.868^{* * *}$ & 0.263 \\
\hline 4 & $-1.666^{\star \star \star}$ & 0.062 & $-1.588^{\star \star \star}$ & 0.059 & $-2.816^{\star * *}$ & 0.316 & $-2.000^{* * *}$ & 0.266 \\
\hline 5 & $-1.734^{\star * *}$ & 0.079 & $-1.872^{* * *}$ & 0.084 & $-2.903^{* * *}$ & 0.323 & $-2.286^{* * *}$ & 0.273 \\
\hline 6 & $-1.877^{\star * *}$ & 0.102 & $-2.120^{* * *}$ & 0.113 & $-3.012^{* * *}$ & 0.329 & $-2.574^{* * *}$ & 0.283 \\
\hline 7 & $-2.253^{* * *}$ & 0.143 & $-2.148^{* * *}$ & 0.136 & $-3.356^{* * *}$ & 0.342 & $-2.584^{* * *}$ & 0.291 \\
\hline 8 & $-2.438^{\star \star *}$ & 0.187 & $-2.111^{\star \star \star}$ & 0.161 & $-3.469^{* * *}$ & 0.359 & $-2.564^{\star * \star}$ & 0.309 \\
\hline 9 & $-2.142^{\star \star \star}$ & 0.196 & $-2.251^{\star \star \star}$ & 0.206 & $-3.143^{\star * *}$ & 0.369 & $-2.792^{\star \star *}$ & 0.330 \\
\hline 10 & $-2.577^{\star \star *}$ & 0.288 & $-1.884^{\star * \star}$ & 0.211 & $-3.444^{* * *}$ & 0.427 & $-2.372^{* * *}$ & 0.338 \\
\hline 11 & $-3.068^{\star * *}$ & 0.418 & $-2.462^{* \star *}$ & 0.314 & $-3.904^{\star * *}$ & 0.531 & $-2.961^{\star * *}$ & 0.414 \\
\hline 12 & $-3.401^{\star * *}$ & 0.587 & $-2.708^{\star \star \star}$ & 0.422 & $-4.364^{\star * *}$ & 0.686 & $-3.220^{* * *}$ & 0.501 \\
\hline 13 & $-4.078^{\star \star *}$ & 1.008 & $-1.880^{\star \star \star}$ & 0.358 & $-5.078^{\star * *}$ & 1.084 & $-2.330^{* * *}$ & 0.439 \\
\hline 14 & $-2.169^{\star \star *}$ & 0.528 & $-1.609^{* * *}$ & 0.414 & $-3.092^{* * *}$ & 0.602 & $-2.154^{* * *}$ & 0.504 \\
\hline 15 & $-2.944^{* *}$ & 1.026 & $-2.944^{\star *}$ & 1.026 & $-3.781^{* * *}$ & 1.056 & $-3.540^{* *}$ & 1.095 \\
\hline Age & & & & & $-0.019^{\star * *}$ & 0.001 & $0.016^{\star \star \star}$ & 0.001 \\
\hline Female (ref male) & & & & & -0.026 & 0.032 & -0.041 & 0.028 \\
\hline Ethnic (ref white) & & & & & $-0.378^{\star * *}$ & 0.089 & 0.098 & 0.080 \\
\hline \multicolumn{9}{|c|}{ Partnership status and desire agreement (ref single) } \\
\hline couple, partner disagrees & & & & & $-0.749^{\star * *}$ & 0.055 & $0.090^{* *}$ & 0.039 \\
\hline couple, partner agrees & & & & & $0.155^{\star * *}$ & 0.039 & $-0.325^{* * *}$ & 0.037 \\
\hline couple, partner's desires missing & & & & & $-0.214^{\star *}$ & 0.079 & $-0.129^{\star *}$ & 0.061 \\
\hline Change in partnership status $t$ to $t+$ & no change) & & & & $1.917^{\star \star \star}$ & 0.064 & $0.260^{\star * \star}$ & 0.077 \\
\hline \multicolumn{9}{|c|}{ Presence and ages of dependent children (ref none) } \\
\hline all children $<5$ & & & & & 0.043 & 0.052 & -0.004 & 0.055 \\
\hline children $>=5$ present & & & & & $-0.290^{\star \star \star}$ & 0.041 & $0.119^{\star \star}$ & 0.037 \\
\hline Child birth $t$ to $t+1$ (ref no birth) ${ }^{2}$ & & & & & $0.383^{* * *}$ & 0.065 & -0.125 & 0.079 \\
\hline \multicolumn{9}{|l|}{ Education level (ref very low/none) } \\
\hline low & & & & & 0.114 & 0.059 & -0.032 & 0.043 \\
\hline medium & & & & & $0.223^{\star \star \star}$ & 0.057 & $-0.087^{\star *}$ & 0.043 \\
\hline high & & & & & $0.456^{* * *}$ & 0.066 & $-0.223^{* * *}$ & 0.056 \\
\hline other/unknown & & & & & 0.032 & 0.176 & 0.004 & 0.141 \\
\hline \multicolumn{9}{|l|}{ Employment status (ref employed) } \\
\hline unemployed & & & & & 0.054 & 0.073 & $-0.194^{\star *}$ & 0.075 \\
\hline out of labour force & & & & & $0.337^{* \star *}$ & 0.042 & $0.132^{* \star *}$ & 0.036 \\
\hline Log household income & & & & & $0.121^{* \star *}$ & 0.028 & 0.020 & 0.023 \\
\hline
\end{tabular}


Housing tenure (ref homeowner)

social renter

private renter

Roomstress

Dislikes neighbourhood (ref likes)

Geographical region (ref Rest of England)

London and SE

Wales

Scotland

N. Ireland

$\mathrm{N}$ (clusters)

Log pseudolikelihood (improvement over null)

Wald chi $^{2}$ (d.f.)

McFadden's pseudo $r^{2}$

AIC

\begin{tabular}{|c|c|c|c|c|}
\hline & $\begin{array}{l}-0.076 \\
1.209^{\star \star *} \\
0.364^{\star \star *} \\
0.221^{\star * *}\end{array}$ & $\begin{array}{l}0.046 \\
0.045 \\
0.057 \\
0.039\end{array}$ & $\begin{array}{l}-0.000 \\
-0.139^{\star *} \\
0.019 \\
-0.856^{\star * *}\end{array}$ & $\begin{array}{l}0.041 \\
0.051 \\
0.059 \\
0.044\end{array}$ \\
\hline & $\begin{array}{l}-0.191^{\star \star \star} \\
-0.281^{\star \star \star} \\
-0.200^{\star \star *} \\
-0.304^{\star \star \star}\end{array}$ & $\begin{array}{l}0.042 \\
0.056 \\
0.051 \\
0.081 \\
\end{array}$ & $\begin{array}{l}-0.097^{\star *} \\
0.070 \\
0.067 \\
0.278^{\star * \star} \\
\end{array}$ & $\begin{array}{l}0.038 \\
0.043 \\
0.044 \\
0.063 \\
\end{array}$ \\
\hline $\begin{array}{l}40234(12557) \\
-37487.557(6714.01) \\
11359.52(30) \\
0.152 \\
75035.115\end{array}$ & $\begin{array}{l}40234(1 \\
-31966.45 \\
12457.02 \\
0.277 \\
64176.90\end{array}$ & $\begin{array}{l}557) \\
(12235.115) \\
122)\end{array}$ & & \\
\hline
\end{tabular}

Source: BHPS, author calculations

${ }^{* *} p<0.05,{ }^{* * *} p<0.001$

${ }^{1}$ Note that extra controls are included for respondent cooperation, housing type and year of interview (not shown)

2 These variables contain categories for unknown values (not shown) 